\title{
19980529059
}

ORNL/CP-96519

\section{A TRANSPARENT ANODE ARRAY DETECTOR FOR 3D ATOM PROBES}

M. K. Miller*

*Metals and Ceramics Division, Oak Ridge National Laboratory, Oak Ridge, TN 37831-6376, USA

RECEIVED

MAR 06 G9S3

In a three dimensional atom probe, the identity and spatial coordinates of the atoms field evaporated from the specimen are determined. ${ }^{1}$ Their identity is calculated from the flight time from the specimen to the single atom detector. The $\mathrm{x}$ and $\mathrm{y}$ coordinates of the atom in the specimen are determined from the coordinates of its impact position on the position-sensitive detector and the $\mathbf{z}$ coordinate is determined from its position in the evaporation sequence. These data may then be reconstructed to visualize and quantify the distribution of all the elements in the specimen. Several types of position-sensitive detectors have been used including a wedge-and-strip detector (positionsensitive atom probe), a 10 by 10 array of anodes (tomographic atom probe), and a gateable CCD camera (optical atom probe). ${ }^{\mathrm{I}}$ The wedge-and strip and the CCD camera detectors both suffer from the limitation that if more than one atom strikes the detector on a field evaporation pulse then the impact positions cannot be determined in many cases. In order to minimize this limitation, Cerezo et al. have developed a dual detector system (optical position-sensitive atom probe) that uses both an 8 by 10 multianode array and an intensified CCD camera. ${ }^{2}$ This dual detector configuration requires a beam splitter which reduces the signal intensity reaching the detectors and two independent detection systems both with image intensifiers. In this paper, an improved version of this detection system that combines these two systems into one is presented.

A schematic diagram of the instrument with the transparent anode array (TAA) detector is shown in Fig. 1. Unlike the 8 transparent-anode detector used in the optical tomographic atom probe, ${ }^{3}$ the TAA is external to the vacuum system. Therefore, it may be used on either linear or energy-compensated instruments and may be used to replace existing detectors. During analysis, the specimen points towards a primary detector consisting of a pair of microchannel plates and a phosphor screen mounted in a conflat flange. The primary detector also provides the ultrahigh vacuum seal. The external TAA consists of a photocathode, a microchannel plate and an integrated phosphor screen and multianode array enclosed in a vacuum envelope, as shown in Fig. 1. The photocathode of the TAA is optically coupled to the primary detector with a large aperture lens. The photocathode is only active during a valid time window so as to reduce the background noise. A CCD camera is similarly optically coupled to the phosphor screen. Improved sensitivity and integration should be achieved if both lenses were replaced with fiber-optic tapers with matching changes on the viewports and CCD camera. In the prototype, the phosphor is deposited on top of a 16 by 2 array of transparent electrically-conducting anodes, as shown in Fig. 2. The 512 by 512 pixel sensor in the CCD camera provides superior spatial resolution for determining the impact position compared to the anodes as each anode maps to 8192 pixels. Each anode on the TAA is connected via a preamplifier to the stop input of a 32 channel time-to-digital convertor (TDC). The start signal for the TDC is obtained from a pickoff of the field evaporation pulse. Each ion is identified from the time-of-flight information from the primary detector. This flight time is then correlated with the time-of-flight information from the multianode array and identifies which anode was struck. Finally, the location of this anode in the array is related to the higher resolution position determined from the CCD camera. The differences in these times provides the flight time from the specimen to the detector and hence the mass-to-charge ratio and the identity of the ion. ${ }^{4}$

1. M. K. Miller, J. Microscopy, 186 (1997) 1-16 and references therein.

2. A. Cerezo et al., Appl. Surf. Sci., 76/77 (1994) 374.

3. B. Deconihout et al., Ultramicroscopy, (1998) in press.

4. This research was sponsored by the Division of Materials Sciences, U.S. Department of Energy under contract DE-AC05-960R22464 with Lockheed Martin Energy Research Corp. This research was conducted utilizing the Shared Research Equipment (SHaRE) User Program facilities at Oak Ridge National Laboratory.

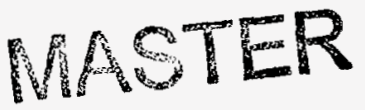

DISTAIBUTION OF THIS DOCUMENT IS UN

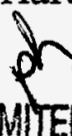

iThe submitted manuscript has been authored by a The submither U. S. Govment under contract No. contacos 


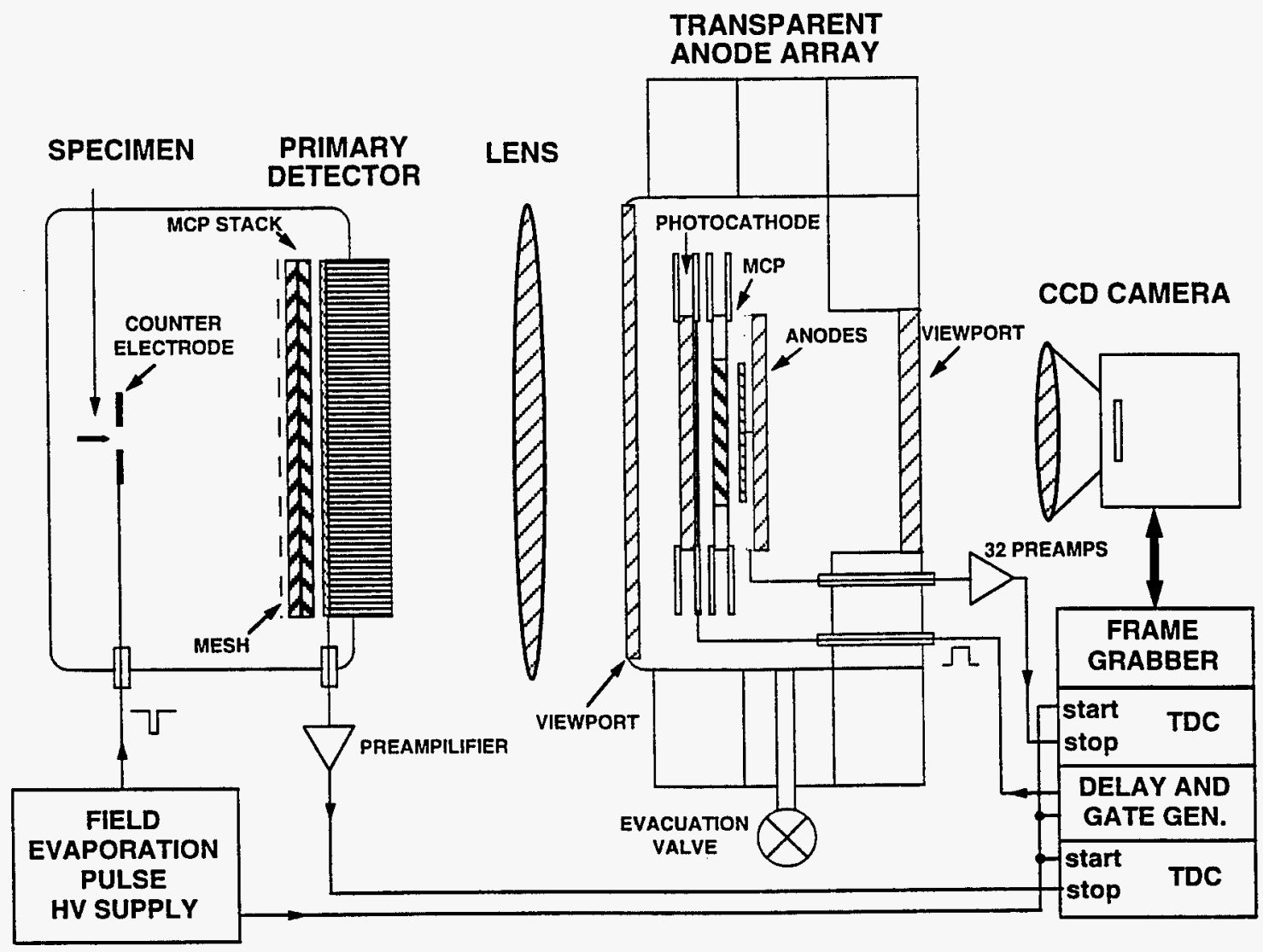

2
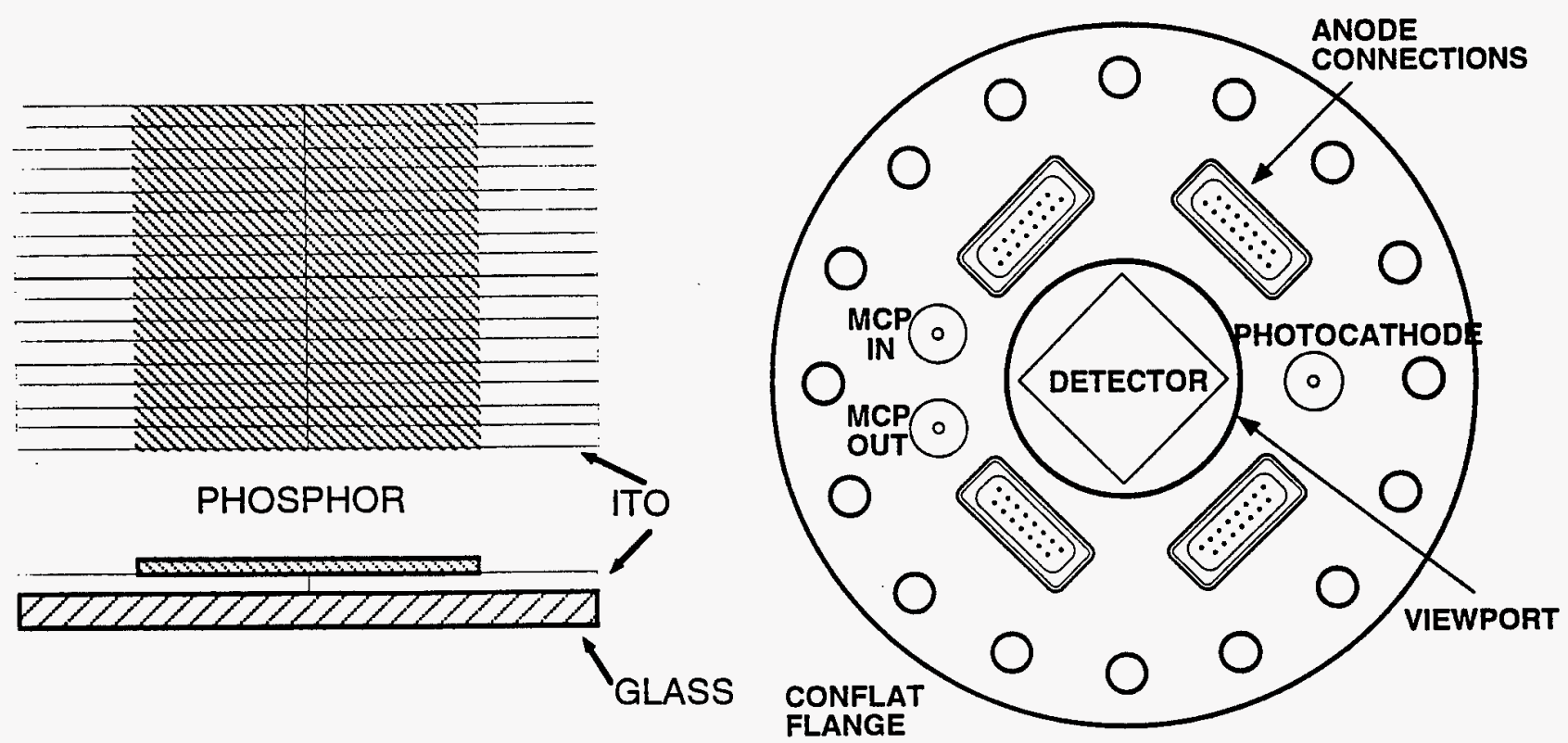

FIG 1. Schematic diagram of a three-dimensional atom probe incorporating the transparent anode array (TAA) detector. The primary detector is in the main vacuum system of the atom probe and all other components are external to the vaccum.

FIG. 2. Top and side view of the anode array and the baseplate of the transparent anode array.. The phosphor is deposited on top of a 16 by 2 array of electrically conducting anodes. 


\section{DISCLAIMER}

This report was prepared as an account of work sponsored by an agency of the United States Government. Neither the United States Government nor any agency thereof, nor any of their employees, makes any warranty, express or implied, or assumes any legal liability or responsibility for the accuracy, completeness, or usefulness of any information, apparatus, product, or process disclosed, or represents that its use would not infringe privately owned rights. Reference herein to any specific commercial product, process, or service by trade name, trademark, manufacturer, or otherwise does not necessarily constitute or imply its endorsement, recommendation, or favoring by the United States Government or any agency thereof. The views and opinions of authors expressed herein do not necessarily state or reflect those of the United States Government or any agency thereof. 
M98005020

||||||||||||||||||||||||||||||||||||||||||||||||||||||||

Report Number (14) $\frac{\text { ORNL/CP-965/9 }}{C O N F-980713-}$

Publ. Date (11) $\quad 199802$

Sponsor Code (18) $D \circ E / E R, X F$
UC Category (19) $U C-4 \circ O, D O E) E R$ 